\title{
EVALUATION OF SIRTUIN 3 BIOMARKER BEFORE AND AFTER EXERCISE REGIMEN IN CHRONIC UNPREDICTABLE MILD STRESS-INDUCED DEPRESSED RATS
}

\author{
SOWNDARYA R, DOSS VA* \\ Department of Biochemistry, PSG College of Arts and Science, Coimbatore, Tamil Nadu, India. Email: victordoss64@gmail.com
}

Received: 23 July 2018, Revised and Accepted: 11 September 2018

ABSTRACT

Objective: Depression is one of the most common psychiatric illnesses that cause disability and public health problems. Physical exercise has been shown to reduce the stress impairment and ameliorate depressive symptoms. The objectives of the present study were to confirm, whether swimming exercise alleviates the depression-like behavior induced by chronic unpredictable mild stress (CUMS) through the alteration in the expression of sirtuin 3 (sirt 3) in brain.

Methods: This study was undertaken to evaluate the possible antidepressant activity of exercise. Female Wistar rats weighing about $120-150$ g were divided into four groups of six animals in each: Control, CUMS-induced, venlafaxine-treated, and exercise-treated groups. The rat model of depression was established using CUMS protocol. Behavioral assessment was performed by sucrose consumption test and forced swim test. Semi-quantitative reverse transcription-polymerase chain reaction and Western blot analysis were performed to study the gene expression and the protein activity of SIRT3.

Results: Our results showed that the gene expression and protein activity of sirt 3 were found to be significantly increased in the exercise-treated group when compared to the depressed group.

Conclusion: The interesting fact from this study is that swimming exercise increases sirt3 expression and possesses a beneficial effect in curing depression.

Keywords: Depression, Venlafaxine, Exercise, Sucrose consumption.

(C) 2019 The Authors. Published by Innovare Academic Sciences Pvt Ltd. This is an open access article under the CC BY license (http://creativecommons. org/licenses/by/4. 0/) DOI: http://dx.doi.org/10.22159/ajpcr.2019.v12i1.28669

\section{INTRODUCTION}

Depression is a most prevalent multifacetico mental disorder characterized by apathy, loss of interest, decreased energy, retardation of thinking, disturbed sleep, and suicidal ideation [1,2]. It is a highly prevalent disabling condition associated with significant morbidity and mortality [3]. It is a common incidence worldwide which affects the quality of life of many people and has become a major cause of suicidal death [4]. Several studies have also shown the involvement of oxidative stress in depressive state [5,6]. Antidepressants are commonly prescribed for depression and other affective disorders. However, these synthetic antidepressants even taken in appropriate doses cause side effects [7].

Sirtuin 3 (SIRT3) is a protein that is encoded by the sirt3 gene. It exhibits $\mathrm{NAD}^{+}$dependent deacetylase activity. SIRT3 expression is highest in metabolically active tissues including the brain, heart, liver, brown adipose tissue, and skeletal muscles. SIRT3 responds to both exercise and nutritional signals in skeletal muscles to correlate downstream molecular responses [8,9]. Exercise causes the cellular adenosine monophosphate (AMP):adenosine triphosphate ratio to increase. Increased levels of AMP trigger activation of AMPactivated protein kinase initiating a signaling cascade promoting SIRT3 expression. Exercise increases SIRT3 expression as well as associated cyclic AMP response element binding phosphorylation and peroxisome proliferator-activated receptor- $\gamma$ coactivator-1 $\alpha$ (PGC $1 \alpha$ ) upregulation [10].

PGC $1 \alpha$ is also induced by exercise and is known to be a key regulator of mitochondrial biogenesis. PGC $1 \alpha$ may play a role in controlling SIRT3 gene expression [10-12]. Brain-derived neurotrophic factor (BDNF) is a protein that belongs to the neurotrophin (nerve growth factor- related proteins) superfamily. The physiological role of BDNF involves the development of the adult CNS to promote, modify, differentiate, and support the survival of neurons. BDNF influences development, survival, maintenance, and plasticity of neurons within the immature and adult nervous system, thus influencing neuronal excitability [13]. Chronic unpredictable mild stress (CUMS) is a well-validated animal model that mimics several human symptoms of depression [14]. This has been used widely for studying clinical depression and effect of antidepressants in diverse drugs [15].

The effect of exercise on depression has long been of interest. Many studies have demonstrated the antidepressant effect of exercise intervention. They support the belief that exercise has been proven effective in improving depression. The latest neuroscience studies have reported that physical activity and exercise can change the levels of brain monoamines and neurotrophic factors, increase synaptic plasticity and neurogenesis, and alter intracellular signaling proteins and neuronal activity $[16,17]$. The beneficial effects of exercise on brain function have been demonstrated in animal models and in a growing number of clinical studies on humans [18]. A study has reported that routine physical exercise prevents depression relapse so much better than antidepressant medication [19].

It is a well-known that exercise can enhance mental ability, cognition, and mental balance. It is proven that exercise induces PGC-1 $\alpha$. Another well-known fact is that PGC-1 $\alpha$ induces SIRT3 level in muscle. However, the same in brains is not studied much. Furthermore, it is proven recently that SIRT3 induces the secretion of BDNF, the all-important and newly discovered brain neurotrophin. This study aims to learn the gene expression of sirt $3, p g c-1 \alpha$, and $b d n f$ and the protein expression of SIRT3 before and after exercise regimen. 


\section{METHODS}

\section{Animals}

Young female Wistar rats were purchased from KMCH, Tamil Nadu, India. Animals were maintained at constant temperature $\left(37^{\circ} \mathrm{C}\right)$, humidity controlled room, and $12 \mathrm{~h}$ light/dark cycle with access to food and water. The ethical clearance for handling of experimental animals was obtained from the Institutional Animal Ethics Committee constituted for the purpose and care of laboratory animals as per guidance of the Committee for the Purpose of Control and Supervision of Experiment on Animals (CPCSEA), Ministry of Social Justice and Empowerment, Government of India (CPCSEA/No: 158/1999/ CPCSEA).

\section{CUMS procedure}

The CUMS protocol was performed according to previous study [20]. Rats were randomly divided into four groups ( $\mathrm{n}=6$ per group): Control group, depression-induced group, venlafaxine-treated group, and exercise-treated group. The control rats were housed together without any disturbance, while the model rats were exposed to following CUMS procedure: Cage tilting (tilt at $45^{\circ} \mathrm{C}$ angle) for $24 \mathrm{~h}$, crowded housing ( 5 rats per cage), noises for $1 \mathrm{~h}$ (alternative periods of noise $10 \mathrm{~min}$ and silence $10 \mathrm{~min}$ ), $24 \mathrm{~h}$ food, $24 \mathrm{~h}$ water deprivation, soiled bedding (wetting cage with water), removal of bedding materials for $12 \mathrm{~h}$, and reversed light-dark cycle, respectively. One stressor was applied per day and the whole stress process was done in random order for 4 weeks. After 4 weeks, the depression behavior was confirmed by forced swim test (FST) and sucrose consumption test (SCT).

\section{Behavior test}

FST

The FST was carried out according to Porsolt et al., 1977 [21]. Here, the experimental rats were made to swim individually in a cylindrical container of $35 \mathrm{~cm}$ in height and $12 \mathrm{~cm}$, such that the rat could not touch the bottom of the cylinder with its limb or tail or climb over the edge of the chamber.

Trial sessions were conducted before the actual 6 min test started. The initial $2 \mathrm{~min}$ in the total $6 \mathrm{~min}$ was not considered, because during the time period, which the animals try to escape out. A rat was considered immobile when it remained floating in water keeping all its limbs motionless, making only little movements to keep its head above water. The total duration of immobility during final 4 min was recorded. The rats were then allowed to dry in a pre-washed enclosure $\left(\sim 32^{\circ} \mathrm{C}\right)$ before being returned to their cages. The decrease in the duration of immobility is a measure of antidepressant activity [22].

\section{SCT}

The test was performed as described previously with few modifications [23]. After $24 \mathrm{~h}$ period of food and water deprivation, each rat was subjected to be in individual cage and was given two bottles containing $1 \%$ sucrose solution and water. The preference for sucrose was calculated as a percentage of consumed sucrose solution of the total amount of liquid consumed.

\section{Exercise protocol}

Rats were trained in a moderate swimming program according to previous procedure [24]. Daily swimming exercise was performed in a large plastic barrel ( $45 \mathrm{~cm}$ in diameter and $60 \mathrm{~cm}$ in height) filled with fresh water $\left(32 \pm 2^{\circ} \mathrm{C}\right)$ to the depth of $50 \mathrm{~cm}$. Exercise was performed at the same time daily (between $10.00 \mathrm{am}$ to $12.00 \mathrm{pm}$ ). After swimming, rats were towel dried and kept warm by electric drier (heater).

The swimming program included two phases: Adaptation and training. During the $1^{\text {st }}$ week (adaptation), the training was begun with $15 \mathrm{~min}$ on the $1^{\text {st }}$ day, and it was increased gradually till $60 \mathrm{~min}$ on the last day [25].

\section{Sample collection}

Brain tissues were harvested to examine the SIRT3 gene expression using semi-quantitative and Western blot analysis.

\section{Isolation of total RNA from brain tissue using TRI reagent}

Total RNA was isolated using TRI reagent (sigma) according to manufacturer's protocol. The collected brain tissue $(100 \mathrm{mg})$ was homogenized in $1 \mathrm{ml}$ of TRI reagent aseptically. The mixture was centrifuged at $12,000 \mathrm{~g}$ for $10 \mathrm{~min}$ at $4^{\circ} \mathrm{C}$, the supernatant was transferred to a fresh tube. Then, added $0.2 \mathrm{ml}$ of chloroform and centrifuged at $12,000 \mathrm{~g}$ for $10 \mathrm{~min}$ at $4^{\circ} \mathrm{C}$. Following centrifugation, the mixture separated into three phases, from which the upper aqueous phase was aspirated carefully into the fresh tube without disturbing the interphase containing DNA. The RNA pellet was precipitated by adding $0.5 \mathrm{ml}$ of ice-cold isopropanol, mixed, and incubated for $10 \mathrm{~min}$ on ice. After incubation, the tubes were centrifuged at $12,000 \mathrm{~g}$ for $10 \mathrm{~min}$ at $4^{\circ} \mathrm{C}$ and the supernatant was discarded completely. To the RNA pellet, $1 \mathrm{ml}$ of ice-cold $75 \%$ ethanol was added and centrifuged at $7500 \mathrm{~g}$ for $10 \mathrm{~min}$ at $4^{\circ} \mathrm{C}$ to wash off the remaining TRI reagent. The supernatant was decanted; the pellet was dried, dissolved in $25 \mu \mathrm{l}$ of RNase-free water, and stored at $-20^{\circ} \mathrm{C}$. RNA concentration was determined using a UV spectrophotometer (Shimadzu) at $260 \mathrm{~nm}$. Quality of RNA was confirmed by calculating 260/280 ratio for detection of protein contamination and by running samples on agarose gel to confirm that the samples are DNA free.

\section{Reverse transcription (RT)}

cDNA synthesis was performed using iScript cDNA synthesis kit (Biorad) according to manufacturer's protocol. Briefly, $20 \mu$ reactions were prepared by combining $4 \mu \mathrm{l}$ iScript reaction mix (containing random and oligo-dT primers), $2 \mu \mathrm{l}$ RNA, $1 \mu \mathrm{l}$ reverse transcriptase, and $13 \mu \mathrm{l}$ nuclease-free water. The reaction was performed by incubating for $5 \mathrm{~min}$ at $25^{\circ} \mathrm{C}$, followed by $30 \mathrm{~min}$ at $42^{\circ} \mathrm{C}$ and $5 \mathrm{~min}$ at $85^{\circ} \mathrm{C}$.

\section{Semi-quantitative RT polymerase chain reaction (RTPCR)}

Semi-quantitative analysis of sirt3 was performed according to previous procedure with few modifications [26,27]. Briefly, simultaneous amplification of both sirt3 and glyceraldehyde-3-phosphate dehydrogenase (gapdh) (housekeeping gene) was performed. Primers (Table 1) for the selected genes were designed using Oligoperfect primer designer (Invitrogen). Gapdh was used as control gene. Primers were purchased from Merck millipore.

The PCR reaction mixture comprising $2 \mu \mathrm{l}$ of cDNA, $5 \mu \mathrm{l}$ of 10X assay buffer, $1 \mu \mathrm{l}$ of $30 \mathrm{mM}$ dNTP mix, $2 \mu \mathrm{l}$ of each forward and reverse oligo nucleotide primers, $1 \mu \mathrm{l}$ of Taq DNA polymerase and $17 \mu \mathrm{l}$ of nuclease free water to a final volume of $30 \mu$ l. PCR was carried out under the following conditions: Initial denaturation at $94^{\circ} \mathrm{C}$ for $2 \mathrm{~min}$, denaturation at $94^{\circ} \mathrm{C}$ for $45 \mathrm{~s}$, and extension at $72^{\circ} \mathrm{C}$ for $1 \mathrm{~min}$. After 35 cycles, the aliquots of PCR products were analyzed by gel electrophoresis with $2 \%$ agarose gel stained in ethidium bromide, photographed under UV light, and the bands were analyzed by ImageJ software.

Table 1: Primers for RT-PCR

\begin{tabular}{lll}
\hline Gene & Primer & Product length \\
\hline gapdh & Fwd : ACCACCATGGAGAAGGCTGG & 267 \\
& Rve: CTCAGTGTAGCCAGGATGC & \\
sirt3 & Fwd: TATCCCAGACTTCAGATCCCCAG & 227 \\
& Rve: ACCCATGAGCTTCAACCAGC & \\
pgc1 alpha & Fwd: TGACATAGAGTGTGCTGCCCTG & 258 \\
& Rve: CTTCTCGAATATGTTCGCGGGC & \\
bdnf & Fwd: GCGGCAGATAAAAAGACTGC & 238 \\
& Rve: GCCAGCCAATTCTCTTTTTG & \\
\hline
\end{tabular}

RT-PCR: Reverse transcription-polymerase chain reaction, $b d n f$ : Brain-derived neurotrophic factor, gapdh: Glyceraldehyde-3-phosphate dehydrogenase, sirt3: Sirtuin 3 


\section{WESTERN BLOT ANALYSIS}

Total protein from brain tissue was extracted in RIPA lysis buffer and quantified by bicinchoninic acid protein assay. Protein samples were separated on $12.5 \%$ sodium dodecyl sulfate polyacrylamide gel electrophoresis and transferred to as nitrocellulose membrane by electroblotting ( $100 \mathrm{~V}$ current for $2 \mathrm{~h}$ ). The membranes were blocked with $5 \%$ non-fat dry milk in TBS $(10 \mathrm{mM}$ Tris, $150 \mathrm{mM} \mathrm{NaCl}, \mathrm{pH} 7.5)$ overnight at $4^{\circ} \mathrm{C}$. All steps were followed by 3 times washing with TBST (0.05\% Tween-20, $10 \mathrm{mM}$ Tris, $150 \mathrm{mM} \mathrm{NaCl}$, pH 7.5) buffer. Next day, the primary antibody (rabbit anti-SIRT3 polyclonal antibody - 1:1000 dilutions) was added to the membranes and kept for $1 \mathrm{~h}$ at $4^{\circ} \mathrm{C}$. After being washed, the membranes were incubated with appropriate antirabbit secondary antibody (diluted 1:5000) for $1 \mathrm{~h}$ at room temperature. Bands were visualized using the ECL substrate. Band intensity was quantified using ImageJ software.

\section{Statistical analysis}

Data were expressed as mean \pm standard deviation. The levels of significant between the groups were determined by performing oneway analysis of variance and Duncan's multiple range test for multiple comparisons among different groups using Statistical Package for the Social Sciences (version 16.0). Differences with $\mathrm{p}<0.05$ were considered to be statistically significant.

\section{RESULTS AND DISCUSSION}

In FST (Table 2), there was a significant $(\mathrm{p}<0.05)$ increase in the immobility time of Group II (depressed rat) compared to the control rats (Group I). After subjecting to swimming exercise, the stressinduced rats showed a significant $(\mathrm{p}<0.05)$ decrease in immobility time when compared to the Group II rats.
In SCT (Table 2), the percentage of sucrose consumption was found to be decreased significantly $(\mathrm{p}<0.05)$ in Group II rats when compared to control group (Group I) and after 4 weeks of exercise regimen, sucrose consumption was found to be increased significantly when compared to the Group II stressed rats, which shows that the exercise reduces the CUMS-induced depression-like behavior in rats.

From Figs. 1 and 2, we found that the gene expression levels of sirt3, proliferator-activated receptor- $\gamma$ (pgc1 $\alpha$ ), and $b d n f$ in depressed rats were much lower than the normal rats. After 4 weeks of exercise regimen, the gene expression levels of sirt3, $p g c 1 \alpha$, and $b d n f$ in treated groups (III and IV) were all improved compared to the depressed groups. The results showed that swimming exercise can increase the gene expression of sirt3, which may be due to the activity of sirt 3 by protecting the brain cells against oxidative stress.

Table 2: Effect of exercise on behavioral changes in depression-induced animal models

\begin{tabular}{|c|c|c|}
\hline \multirow[t]{2}{*}{ Groups } & FST & SCT \\
\hline & $\begin{array}{l}\text { Duration of } \\
\text { mobility in seconds }\end{array}$ & $\begin{array}{l}\text { Sucrose } \\
\text { preference in \% }\end{array}$ \\
\hline Normal control & $37.96 \pm 6.14$ & $91.20 \pm 1.45$ \\
\hline Depression induced & $114.06 \pm 9.52^{*}$ & $72.27 \pm 4.06^{*}$ \\
\hline $\begin{array}{l}\text { Depression+drug } \\
\text { treated }\end{array}$ & $57.18 \pm 8.19 *$ & $89.60 \pm 2.40^{*}$ \\
\hline $\begin{array}{l}\text { Depression+exercise } \\
\text { treated }\end{array}$ & $70.52 \pm 4.35^{*}$ & $90.05 \pm 0.53 *$ \\
\hline
\end{tabular}

Data are expressed in mean \pm SD $(n=6),{ }^{*} \mathrm{p}<0.05$ - significant. SD: Standard deviation, FST: Forced swim test, SCT: Sucrose consumption test

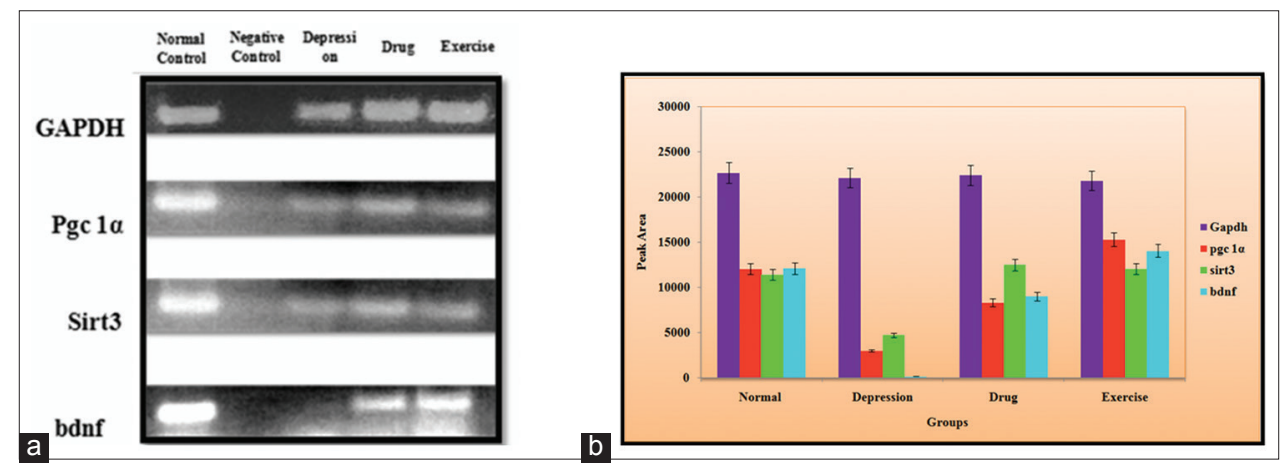

Fig. 1: Effect of exercise on mRNA expression of sirtuin 3 (sirt3) in brain tissue using semi-quantitative reverse transcription-polymerase chain reaction (RT-PCR). (a) Semi-quantitative RTPCR - gene expression of sirt3: Groups - normal control, chronic unpredictable mild stress-induced depression, venlafaxine-treated rats, and exercise-treated rats. Glyceraldehyde-3-phosphate dehydrogenase, peroxisome proliferator-activated receptor- $\gamma(p g c 1 \alpha)$ coactivator-1 $\alpha$, sirt3 - sirtuin 3, and brain-derived neurotrophic factor (bdnf). Depressed rats showed decreased $p g c 1 \alpha$, sirt 3 , and $b d n f$ expression than the normal rats. Drug- and exercise-treated rats showed increased expression of pgc1 $\alpha$, sirt3, and $b d n f$ compared to untreated rats. (b) Band intensities were quantified using peak area, ${ }^{*} p<0.05$ - significant

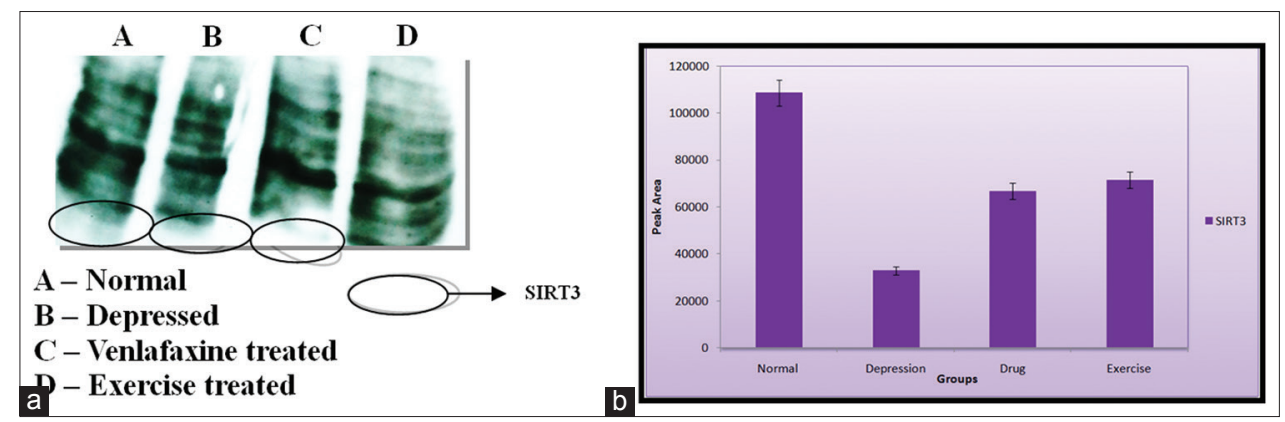

Fig. 2: Western blot of sirtuin 3 (SIRT3). (a) The circles indicate the $28 \mathrm{kDa}$ SIRT3 protein expression in the experimental groups. It is to be highlighted that that the SIRT3 normal (A) expression is reduced during depression (B) and increases efficiently during venlafaxine(C) and exercise-treated rats (D). (b) - Band intensities were quantified using peak area, ${ }^{*} \mathrm{p}<0.05$ - significant. 
Furthermore, the increased expression of SIRT3 in exercised groups was confirmed by Western blotting analysis (Fig. 2). We found that the protein expression level of SIRT3 was significantly decreased in untreated groups. After the exercise treatment, the SIRT3 level was found to be increased significantly in treated groups (III and IV), which were essentially in agreement with that of the gene expression level of sirt3. Therefore, this assay confirmed that the exercise possesses neuroprotective effect by increasing the sirt3 level in brain during depressed conditions.

\section{DISCUSSION}

In this present study, we validated, whether swimming exercise alleviates the depression-like behavior induced by chronic stress through the alteration in the expression of sirt 3 in brain. Stress is known to exacerbate depression in susceptible individuals [28]. Here, we aimed to establish CUMS rat model with depression-like behavioral changes by performing stress procedures, as the CUMS-induced animal model mimicked the human depression [29]. After analyzing the depressed conditions, swimming exercise procedure was followed for 28 days. Semi-quantitative RT-PCR and Western blot analysis were performed to study the gene expression and the protein activity of SIRT3.

FST is a commonly used behavioral despair model in depression [30]. Sucrose preference is considered as one of the symptoms of depression, leading to anhedonia indicating loss of interest [31,32]. Both tests are quite sensitive and relatively specific to confirm the depressive symptoms [21]. Here, we found increase in immobility time in FST and a remarkable reduction in sucrose preference in Group II (depressed) rats reflecting the state of behavioral despair, which were claimed to reproduce a condition similar to human depression [33]. After the exercise treatment, there was a significant decrease in immobility time and significant increase in the sucrose consumption.

In gene expression study, the expression of sirt 3 in brain was significantly decreased in CUMS-induced depressed rats, which may be caused due to the damage induced by CUMS in brain cells. After the treatment, the recent study shows that the enzyme SIRT3 protects brain cells against stresses and also found that physical exercises increase the expression of SIRT3, helping to protect the brain against degeneration [34]. Moreover, it was reported that sirt3 overexpression protects cultured motor neurons against the cell death promoting effect of SOD1 mutation that suggests the neuroprotection role of SIRT3 [35]. SIRT3 promotes activation of antioxidant systems, fatty acid oxidation, and neuroprotection. Thus, SIRT3 activity can reduce reactive oxygen species (ROS) levels by directly modulating key antioxidant enzymes, thereby acting as a shield against oxidative damage. Hence, it is possible that exercise activates PGC- $1 \alpha$ and SIRT3. Increased SIRT3 lowers ROS-mediated DNA damage. Furthermore, overexpression of SIRT3 has been shown to significantly increase neuronal life span [36]. The antioxidant and metabolic effects mediated by SIRT3 suggest a potential neuroprotective role through improved mitochondrial function, which subsequently results in increased neuronal survival and reduced aging effects. The Western blot analysis of SIRT3 also showed the increased protein expression in treated groups when compared to the depressed groups. Thus, our data prove the antidepressant-like effect of exercise in CUMS-induced depressed rats.

\section{CONCLUSION}

It is found that the exercise could reverse the anhedonic behavior before and after exercise. CUMS-induced behavioral changes were ameliorated by chronic exercise and antidepressant medications. In this study, correlating sirt 3 to depression through semi-quantitative RT-PCR and Western blotting revealed decreased expression in the depressed group when compared to treated (drug and exercise) groups that show increased expression than the depressed group and similar to the normal group. Thus, our data suggest that sirt 3 expression can be associated to pathogenesis of depression and exercise can be used to treat depression.

\section{ACKNOWLEDGMENT}

The authors are much thankful to University Grant Commission (UGC), New Delhi, for providing financial support under Minor Research Project (F.No:4-4/2013-14(MRP-SEM/UGC-SERO)).

\section{AUTHORS' CONTRIBUTION}

Sowndarya. R and Dr. Doss VA designed the experiment. Sowndarya. R performed the experiment and prepared manuscript. Final approval of the article was done by (Associate Prof) Dr. Doss VA.

\section{CONFLICTS OF INTEREST}

There are no conflicts of interest.

\section{REFERENCES}

1. Yu ZF, Kong LD, Chen Y. Antidepressant activity of aqueous extracts of Curcuma longa in mice. Ethanopharmocol 2002;83:161.

2. Pamulaparthi A, Prathap VR, Banala M, Nanna RS. Experimental evaluation of antidepressant and antianxiety activities of aqueous leaf extracts of Senna alata (L.) Roxb. using in vitro animal models. Int J Curr Pharm Res 2016;8:60-3

3. Paul EH, Charles BN. Advances in the treatment of depression. Neurotherapeutics 2006;3:42.

4. Pati D, Pandey DK, Mahesh R, Vand K, Jhadev HR. Antidepressantlike activity of Mucuna pruriens: A traditional indian herb in rodent models of depression. Pharmacol Online 2010;1:537-51.

5. Sarandol A, Sarandol E, Eker SS, Erdine S, Vatansever E, Kirli S. Major depressive disorder is accompanied with oxidative stress: short-term antidepressant treatment does not alter oxidative-antioxidative systems. Human Psycho Pharmacol Clin Exp 2007;22:67-73.

6. Eren M, Naziroglu M, Demirdas A, Celik O, Uguz AC, Altunbasak A, et al. Venlafaxine modulates depression induced oxidative stress in brain and medulla of rat. Neurochem Res 2007;32:497-505.

7. Tiwari P, Pratap SR, Ritesh J, Misha R. Antidepressant activity of hydroalcoholic extract of Zingiber officinale. Int Res J Pharm 2012;3:149-51.

8. Michan S, Sinclair D. Sirtuins in mammals: Insights into their biological function. Biochem J 2007;404:1-13.

9. Saunders LR, Verdin E. Sirtuins: Critical regulators at the crossroads between cancer and aging. Oncogene 2007;26:5489-504.

10. Palacios OM, Carmona JJ, Michan S, Chen KY, Manabe Y, Ward JL, et al. Diet and exercise signals regulate SIRT3 and activate AMPK and PGC-1alpha in skeletal muscle. Aging 2009;15:771-83.

11. Finck BN, Kelly DP. PGC-1 coactivators: Inducible regulators of energy metabolism in health and disease. J Clin Invest 2006;116:615-22.

12. Handschin C, Spiegelman BM. Peroxisome proliferator activated receptor (gamma) coactivator 1 coactivators, energy homeostasis and metabolism. Endocr Rev 2006;27:728-35.

13. Castren E, Rantamaki T. The role of BDNF and its receptors in depression and antidepressant drug action: Reactivation of developmental plasticity. Dev Neurobiol 2010;70:289-97.

14. Willner P. Validity, reliability and utility of the chronic mild stress model of depression: A 10-year review and evaluation. Psychopharmacology (Berl) 1997;134:319-29.

15. Redrobe JP, Bourin M, Colombel MC, Baker GB. Dose-dependent noradrenergic and serotonrgic properties of venlafaxine in animal models indicative of antidepressant activity. Psychopharmacology 1998; $138: 1-8$

16. Greenwood BN, Fleshner M. Exercise, stress resistance, and central serotonergic systems. Exerc Sport Sci Rev 2011;39:140-9.

17. Paluska SA, Schwenk TL. Physical activity and mental health: Current concepts. Sports Med 2000;29:167-80.

18. Lin TW, Kuo YM. Exercise benefits brain function: The monoamine connection. Brain Sci 2013;3:39-53.

19. Strawbridge WJ, Deleger S, Roberts RE, Kaplan GA. Physical activity reduces the risk of subsequent depression for older adults. Am J Epidemiol 2002; 156:328-34.

20. Nirmal J, Babu CS, Harisudhan T, Ramanathan M. Evaluation of behavioral and antioxidant activity of Cytisus scoparius Link in rats exposed to chronic unpredictable mild stress. BMC Complement Altern Med 2008;8:15.

21. Porsolt RD, Bertin A, Jalfre M. Behavioral despair in mice: A primary screening test for antidepressants. Arch Int Pharmacodyn Ther 1977;229:327-36. 
22. Borah A, Singha B, Phukan S. Antidepressant effect of ceftriaxone in forced swimming test and in tail suspension test in mice. Int J Pharm Pharm Sci 2016;8:191-4

23. Lin J, Wu PH, Tarr PT, Lindenberg KS, St-Pierre J, Zhang CY, et al. Defects in adaptive energy metabolism with CNS-linked hyperactivity in PGC-1alpha null mice. Cell 2004;119:121-35.

24. Liu X, Yanj LJ, Fan SJ, Jiang H, Pan F. Swimming exercise effects on the expression of HSP70 and iNOS in hippocampus and prefrontal cortex in combined stress. Neurosci Lett 2010;476:99-103.

25. Contarteze RV, Fde BM, Gobatto CA, Mello MA. Stress biomarkers in rats submitted to swimming and treadmill running exercises. Comp Biochem Physiol A Mol Integr Physiol 2008;151:415-22.

26. Noonan KE, Beck C, Holzmayer TA, Chin JE, Wunder JS, Andrulis IL, et al. Quantitative analysis of MDRI (multidrug resistance) gene expression inhuman tumors by polymerase chain reaction. Proc Natl Acad Sci 1990;87:7160-4.

27. Kinoshita T, Imamura J, Nagai H, Shimotohno K. Quantification of gene expression over a wide range by the polymerase chain reaction. Anal Biochem 1992;206:231-5.

28. Gold PW, Chrousos GP. Organization of the stress system and its dysregulation in melancholic and atypical depression high vs low CRH/NE stress. Mol Psychiatry 2002;7:254-75.

29. Willner P, Muscat R, Papp M. Chronic mild stress-induced anhedonia:
A realistic animal model of depression. Neurosci Biobehav Rev 1992; 16:525-34

30. Patel SS, Rajshree N, Shah PV. Evaluation of antidepressant activity of herbomineral formulation. Int J Pharm Pharm Sci 2016;8:145-7.

31. Kalueff AV, Gallagher PS, Murphy DL. Are serotonin transporter knockout mice depressed?: Hypoactivity but in anhedonia. Neuroreport 2006;17:1347-51.

32. Strekalova T, Gorenkova N, Schunk E, Dolgov O, Bartch D. Selective effects of citalopram in a mouse of stress-induced anhedonia with a control for chronic stress. Behav Pharmacol 2006;17:271-87.

33. Willner P. The Validity of animal models of depression. Psychopharmacology 1984;83:1.

34. Cheng A, Yang Y, Zhou Y, Maharana C, Lu D, Peng W, et al. Mitochondrial SIRT3 mediates adaptive responses of neurons to exercise and metabolic and excitatory challenges. Cell Metab 2015;23:128-42.

35. Song W, Song Y, Kincaid B, Bossy B, Bossy-Wetzel E. Mutant SOD $1^{\mathrm{G} 93 \mathrm{~A}}$ triggers mitochondrial fragmentation inspinal cord motor neurons: Neuroprotection by SIRT3 and PGC1 $\alpha$. Neurobiol Dis 2013;51:72-81.

36. Wier HJ, Murray TK, Kehoe PG, Love S, Verdin EM, O’Neill MJ, et al. CNS SIRT3 expression is altered by reactive oxygen species and in Alzheimer's disease. PLoS One 2012;7:e48225. 